A R T I G O

\title{
INSURGENTES INCENDEIAM A CIDADE DA BAHIA. O QUEBRA BONDES E A REVOLUÇÃO DE 30
}

Insurgents set fire to the city of Bahia.

The tramway riot and the October Revolution of 1930

Los insurgentes queman la ciudad de Bahia.

El motín de tranvía y la Revolución de Octubre de 1930

ANTONIO LUIGI NEGRO ${ }^{I^{*}}$
JONAS BRITO ${ }^{I^{* *}}$

DOI: http://dx.doi.org/10.1590/S2178-14942020000300008

'Universidade Federal da Bahia - Salvador (BA), Brasil.

*Pesquisador do Conselho Nacional de Desenvolvimento Científico e Tecnológico (CNPq), pós-doutorado no Centro de Pesquisa e Documentação de História Contemporânea do Brasil (CPDOC) e professor do Departamento de História da Universidade Federal da Bahia (UFBa) (negro@ufba.br).

(D) http://orcid.org/0000-0001-7253-355X

"Universidade Estadual de Campinas - Campinas (SP), Brasil.

**Doutorando em História pela Universidade Estadual de Campinas (Unicamp), bolsista da Fundação de Amparo à Pesquisa do Estado de São Paulo (FAPESP), processo n 2017/08502-6) (brito.jonas@outlook.com).

(D) https://orcid.org/0000-0001-6567-4717

Artigo recebido em 30 de abril de 2020 e aprovado para publicação em 03 de julho de 2020. 


\title{
RESUMO
}

A partir da análise do Quebra Bondes, protesto ocorrido em 4 de outubro de 1930 contra as companhias Linha Circular e Energia Elétrica, firmas encarregadas dos bondes, elevadores, planos inclinados, eletricidade e telefonia de Salvador, o artigo questiona a costumeira representação da elite baiana de placidez social ou controle da população durante o processo "mudancista" - "outubrista" - em 1930. Nossa intenção estratégica é integrar a pesquisa sobre a Bahia na macronarrativa histórica com termos distantes das perspectivas que a enquadram como um lugar atrasado ou marginal no processo político brasileiro. Para nós, a Bahia aparece muito e desde o começo da Revolução de 30. Legalista no início, o estado aderiu aos vitoriosos (sem resistir). Neste artigo, a Bahia, contudo, não é vira-casaca: é, antes, lugar atravessado pela possibilidade da ação popular direta, pela presença de sertanejos armados por seus patrões, pela conspiração civil e militar e, por fim, pelas forças oligárquicas aliadas a São Paulo. Em particular, o artigo aponta para a força popular no enfrentamento de obstáculos reais, tanto as hierarquias sociais quanto as distâncias existentes entre os pontos da cidade onde agiram os insurgentes. Examina como o quebra-quebra foi percebido em termos raciais e não teve sua paternidade reivindicada por nenhuma força operante no movimento revolucionário, talvez porque tenha projetado sobre a antiga capital do Brasil a caraça de malvadezas do bicho-papão da horda negra.

PALAVRAS-CHAVE: Revolução de 30; Bahia; Motim; Trabalhadores; Racismo.

\begin{abstract}
Based on the analysis of a streetcar riot that took place on October 4, 1930 against the Companhia Linha Circular ande Energia Elétrica, both firms in charge of trams, elevators, inclined planes, electricity and telephony in Salvador, the article examines the usual representation of the Bahian elite of social placidity or control over the population during the October Revolution of 1930. Our strategic intention is to integrate the research on Bahia into macro historical account in terms that differ from the perspectives that frame it as a backward or marginal place in the Brazilian political process. For us, Bahia appears a lot and since the beginning of the revolution. Legalist in the beginning, the state has joined the victorial rebels without resisting. In this article, Bahia, however, is not a turncoat: it is rather a place fractured by the possibility of direct popular action, by the presence of men armed by their bosses, by the civil and military conspiracy and, finally, by the oligarchic forces allied to São Paulo. In particular, the article points to the popular force facing real obstacles, either the social hierarchies or the existing distances between the areas the city where the insurgents acted. It examines how the riot was perceived in racial terms and why its authorship was not claimed by any operating force in the revolutionary movement.
\end{abstract}

KEYWORDS: October Revolution; Bahia; Riot; Workers; Racism.

\section{RESUMEN}

A partir del análisis del "rompe-tranvías", protesta que tuvo lugar el 4 de octubre de 1930 contra las compañías Linha Circular e Energia Elétrica, empresas encargadas de los tranvías, ascensores, planos inclinados, electricidad y telefonía en Salvador, el artículo cuestiona la representación habitual de la placidez social o el control de la población durante el proceso revolucionario en 1930. Nuestra intención estratégica es integrar la investigación sobre Bahía en la macronarrativa histórica en términos muy alejados de las perspectivas que la enmarcan como un lugar atrasado o marginal en el proceso político brasileño. Para nosotros, Bahía aparece mucho y desde el comienzo de la Revolución de 1930. Legalista al principio, se ha unido a los rebeldes vencedores sin resistir. En este artículo, Bahia no es un traidor: es más bien un lugar atravesado por la posibilidad de la acción popular directa, por la presencia de peones armados por sus jefes, por la conspiración civil y militar y, finalmente, por las fuerzas oligárquicas aliadas a São Paulo. En particular, el artículo señala la fuerza popular para enfrentar los obstáculos reales, tanto las jerarquías sociales como las distancias existentes entre los puntos de la ciudad donde actuaron los insurgentes. Examina cómo se percibía el motín en términos raciales sin su paternidad reclamada por fuerza revolucionaria ninguna.

PALABRAS CLAVE: Revolución de Octubre; Bahia; Motín; Trabajadores; Racismo. 
m 1947, em réplica ao ex-ministro da Justiça Viana do Castelo, Aluísio de CarvaIho Filho discordou de, antes de 24 de outubro de 1930, terem "todos os governos estaduais" ruído, "do Espírito Santo ao extremo norte". Carvalho Filho afirmou que, na Bahia, as autoridades permaneceram coesas, "cumprindo sua missão". O povo em Salvador "não perdera o sentido da ordem", apesar dos "tumultos", concentrados sobre a empresa estadunidense Electric Bond and Share Company (Ebasco), firma concessionária dos serviços públicos de transporte e energia (Carvalho Filho, 1968: 6-8). Nos anos 1980, o banqueiro Clemente Mariani apontou de novo para essa coesão, arrodeada na candidatura do governador da Bahia Vital Soares à vice-presidência da República (em chapa encabeçada pelo governador de São Paulo Júlio Prestes). "Nem se falava em revolução", garantiu. Um "Quebra Bondes" foi "abafado pela polícia". Ao deporem o presidente Washington Luís no Rio, entregou-se a administração estadual ao comandante da Região Militar, e aí "chegaram os revolucionários". Quando desocupada de soldados, "a Bahia inteira se retraiu". E "foi isto a revolução na Bahia" (Lima, 1986: 88).

Esclarecendo que, nessa época, Bahia e Salvador designavam juntos a capital soteropolitana, este artigo questiona essa representação altaneira da elite baiana de placidez ou controle da população durante o processo "mudancista" - "outubrista" — em 1930. Nosso objetivo imediato é identificar as incertezas da Revolução de 1930, tendo em mira o Quebra Bondes, protesto ocorrido em 4 de outubro contra as companhias Linha Circular e Energia Elétrica, firmas subsidiárias da Ebasco encarregadas dos bondes, elevadores, planos inclinados, eletricidade e telefonia'. Como revelou Luís Sant'Ana, embora a Bahia tenha permanecido leal a Washington Luís até o fim, o motim — na receosa alusão do cônsul dos Estados Unidos — projetou sobre a antiga capital do Brasil a caraça de malvadezas do "bicho-papão da horda negra" (Sant'Ana, 2010: 92).

Em segundo lugar, ao questionarmos a negativa do teor turbulento e popular da Revolução de 30, examinamos as forças políticas e sociais envolvidas no protesto social, as relações com os grupos e classes sociais atuantes no movimento revolucionário e a acomodação nos planos estadual e nacional. Nossa intenção estratégica é integrar na macronarrativa histórica a pesquisa sobre a Bahia em termos distantes das perspectivas que a enquadram como um lugar atrasado ou deslocado. Em livro sobre as imagens da revolução, a Bahia não só aparece no fim, mas também aparece pouco (eram certamente desconhecidas as fontes visuais do protesto popular em Salvador). De três retratos, dois são de missas rezadas em prol do triunfo mudancista (Murakami, 1980: 167-169). Diversamente, a Bahia 
aparece muito e desde o começo. Neste artigo, a Bahia — já em conflito aberto desde a segunda jornada pública e nacional da revolução — não é vira-casaca, não é lugar que adere a fato consumado sem desempenho de relevo. É, sim, lugar atravessado pela possibilidade da ação popular direta, pela marcha de sertanejos armados por seus patrões, pela conspiração civil e militar e, por fim, pela proeminência nacional de suas forças oligárquicas aliadas a São Paulo. Noutro livro, lê-se que a Bahia foi previsivelmente "pega no lado errado da cerca" (Borges, 1992: 43), isto é, com o seu governador eleito vice-presidente na chapa encabeçada por Júlio Prestes. Deixando de lado o equívoco do juízo sobre dois lados (um certo, outro errado), este artigo aponta para a força popular no enfrentamento de obstáculos reais, tanto as hierarquias sociais quanto as distâncias mesmo existentes entre os pontos da cidade onde agiram os insurgentes.

O Quebra Bondes aconteceu em instante delicado da Revolução de 30. A luta armada tinha acabado de começar no Rio Grande do Sul, em 3 de outubro. No Norte, teatro das operações onde estava encaixada a Bahia, a revolução estourou na Paraíba depois da meia-noite. Com o levante noticiado na imprensa vespertina de Salvador do dia 4, sua deflagração na Bahia era incerta. Apesar de a conspiração existir, permaneceu retraída nos quartéis. 0 movimento não era público e notório nas ruas, muito menos no dia a dia da população. Não houve canhoneio nos fortes, também não houve movimentação de soldados ou tomada de posições. 0 motim, então, não foi precedido pela conclamação do povo pela tropa. Bem menos conhecido ainda era o desfecho do processo apenas iniciado, momento muito diferente de quando aconteceram os empastelamentos e confronto sucedidos no fim, quando a multidão em São Paulo e no Rio já sabia que havia uma revolução nas ruas, enxergava os lados e a vitória dos rebeldes podia ser dada como certa.

Em acréscimo, embora nossas pesquisas nos incitem a explorar as pistas indiciárias do peso da Bahia no complô conspiratório contra a Presidência da República, vamos deixar de lado esse seu papel no drama outubrista para analisar a multidão plebeia das ruas, negra e operária. Para nós, o Quebra Bondes foi mais uma demonstração da surpreendente e impactante presença da classe trabalhadora na História do Brasil. Na trama tenentista sob o comando de Juarez Távora (Lopes, 2014), a Bahia, apesar de dobrar com Vital Soares a chapa de Júlio Prestes, também figurava nos planos da luta revolucionária logo no dia 4, objetivo, contudo, irrealizado (Silva, 1980: 49). Mesmo assim, os insurgentes mostraram ser capazes de abalar a cidade em poucas horas, sem a certeza do ascenso de uma revolução em todo o país. Foi a sua energia que ligou a Bahia aos fronts pernambucano e paraibano, sem o comando ou apoio militares. 
Contudo, exceção à queixa dos prejuízos, o pós-30 faz referência ao Quebra Bondes como explosão de vândalos numa sociedade tradicional de ordem, placidez e de longo convívio e amizade entre famílias poderosas e de bem. No seu próprio tempo e lugar, nem os tenentes, nem o poder estadual situacionista, tampouco a oposição quiseram assumir a paternidade pelo movimento. Por isso o título faz referência a insurgentes, e não a revolucionários. Pelos termos descritores visíveis na materialidade das evidências históricas, os insurgentes são os descalços, o "zé-povinho", a horda negra². No convívio cotidiano, sua simples presença já amedrontava. Tremores são evidentes, por exemplo, nas lembranças do filho do chefe de polícia Madureira de Pinho. Em sua autobiografia, ele se lembrou, "logo que nos mudamos para lá" — o rico bairro da Vitória — , assaltou-Ihe "o ruído surdo dos atabaques". Sobressaltavam "muitas de minhas noites". Diziam "ser o eco de candomblés que batiam na baixa da Graça. Isso e o uivo dos cães anônimos me perturbavam muitas noites de sono!" (Pinho, 1974: 51).

Perceber as negativas da classe dominante quanto ao caráter desconcertante da Revolução de 30 e evidenciar aquilo que a perturbava nos permite questionar a representação coletiva da nossa sociedade como um lugar sem diferenças raciais ou tensões de classe, cuja razão de ser é um nacionalismo protagonizado por sábios homens brancos, que negam a existência de raças e classes. Analisamos então a linguagem reveladora dos horizontes de classe e das concepções racistas dominantes na Bahia e no Brasil, assim como a estrangeira. "Esta carta diz que a senhora não é um desses repórteres sensacionalistas. Ótimo", alegrou-se o ministro Osvaldo Aranha perante a antropóloga Ruth Landes, em 1938. "O Brasil precisa ser corretamente conhecido", afirmou, apontando especialmente para a "situação política". Ciente, pela carta, dos planos dela de estudar os negros da Bahia, Aranha garantiu que o "atraso político" tinha tornado "esta ditadura necessária" (o Estado Novo), explicada "perfeitamente pelo nosso sangue negro" (Landes, 2002: 41).

Se algum grupo tivesse querido se valer do descontentamento popular para dirigir a insurgência contra a ordem em vigor, a História da Revolução de 30 seria bem diferente do elitismo racista de Osvaldo Aranha. Na Imagem 1, na praça principal do poder político da Bahia, onde os trâmueis davam a volta para o transporte de passageiros, vê-se à esquerda a joia art déco da engenharia mundial, o elevador Lacerda, então recentemente aberto ao público (sucedâneo do antigo elevador da Conceição, sobre a ladeira homônima, cujo sobe e desce se transferiu em parte aos elevadores).

A revolta foi uma forma de se chocar de frente com a deterioração das condições de trabalho e, portanto, de sobrevivência. A populaça se constituía de trabalhadores que precisavam de cada dia para sobreviverem. Assalariados ou informais, "o fato de serem gente 


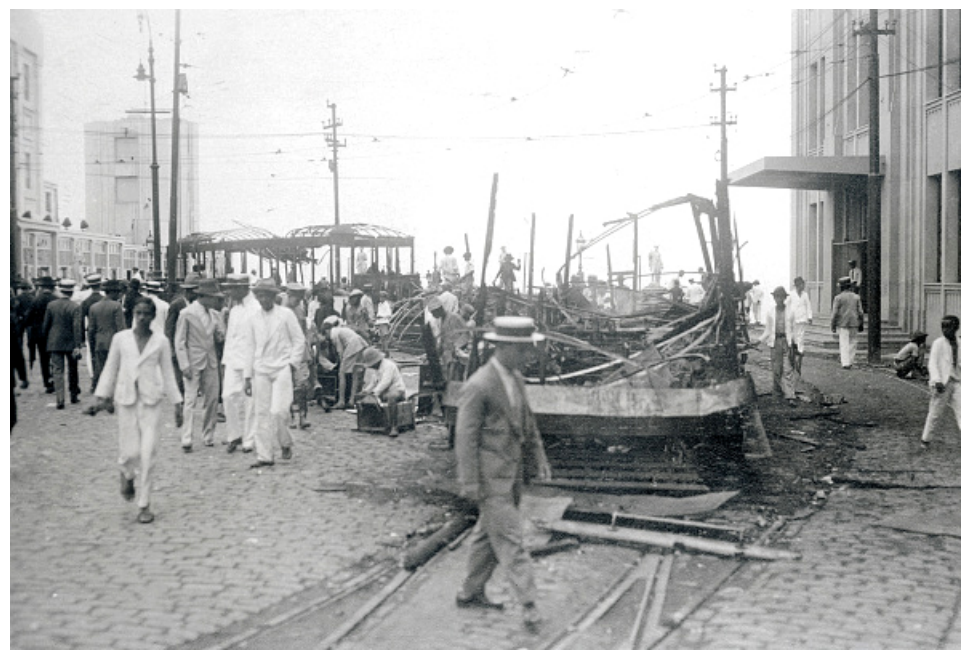

Imagem 1 - A praça do elevador Lacerda no dia seguinte ao Quebra Bondes. Fonte: Getty Images 515143184, adquirida em 26/4/2020.

urbana" - como escreveu João Reis a respeito da greve dos ganhadores de 1857 — evidenciava-se na "sua importância para o funcionamento da cidade, inserida num mercado de trabalho monetarizado", o que "explica em parte o estilo de resistência escolhido" (Reis, 1993: 29). E parece-nos que o ícone erguido em praça pública não foi o fantasioso bicho-papão. Outra figura foi descarregada das nuvens perto do terreiro de Jesus, sem necessidade de pai ou mentor intelectual. Entre a noitinha e a madrugada, os protestos do dia 4 em Salvador se espalharam do centro histórico para o subúrbio de Itapagipe (estações e oficinas), Dique (usina) e Retiro (pedreira). Segundo perícia policial, saquearam, apedrejaram e incendiaram usinas, escritórios, os elevadores Lacerda e Taboão e o Plano Inclinado do Pilar. Só um automóvel, mais de 80 bondes (65\% da frota), aparelhos elétricos e telefônicos foram destruídos pela ira e força muscular da multidão. 0 Instituto Luso Brasileiro e a antiga casa do Barão de Cotegipe arderam em chamas na Cidade Baixa e no Bonfim, respectivamente. Na praça Castro Alves, verificou-se ataque à sede própria do jornal $A$ Tarde (outro prédio art déco então inaugurado), que tinha apoiado o anúncio de aumento de preços. 0 prejuízo às subsidiárias da Ebasco foi calculado entre um e dois milhões de dólares ${ }^{3}$.

0 quebra-quebra foi resposta aos abusos de um cotidiano de descontentamentos. Era grande a insatisfação contra a carestia, o aumento nos preços em 1929 e a má qualidade dos serviços de eletricidade, comunicação e transporte, em grande parte causada pela ausência de conservação e capacidade do sistema operado pelas companhias Circular e Elétrica. Contra 
os telefones, encontramos poucas reclamações, embora nelas conste serem comuns ligações com demoras, erros e interrupções. 0 serviço piorara desde a inauguração, com o número de aparelhos por telefonista tendo passado de 120 para 400 (A Tarde, 16/4/1927; 26/7/1927)4. Já o fornecimento de energia registrava síncopes, chegando a prejudicar a circulação de bondes (O Imparcial, 30/5/1926; A Tarde, 1/3/1929 e 28/6/1929). Postes podres e eletrizados, cabos de força rompidos e sua proximidade com fachadas prediais ocasionavam acidentes, choques e curtos-circuitos (O Imparcial, 18/6/1926; A Tarde, 13/7/1929). Um carregador foi morto por cabo aéreo na Preguiça, ao colocar a cabeça pelo óculo do depósito em que trabalhava em 1926, mesmo destino de empregada doméstica na janela da residência de seus patrões da Cruz do Pascoal (Diário de Notícias, 19/3/1926; A Tarde, 7/3/1930).

Os cartões postais do lugar — seus ascensores (Lacerda, Taboão) e planos inclinados (Gonçalves e Pilar) - não davam vazão ao fluxo entre as cidades Alta e Baixa, formando-se filas nas horas de pico, sob sol, chuva e, pior, com o risco de o camarim paralisar, aumentando a espera, a fadiga, a irritação e apreensões (Diário de Notícias, 10/2/1926; O Imparcial, 29/4/1926 e 16/5/1926; A Tarde, 17/11/1926, 8/5/1928 e 28/6/1929). A superlotação nos bondes era cotidiana e, por outro lado, veículos particulares e de praça eram poucos e caros (Diário de Notícias, 10/3/1926; O Imparcial, 16/5/1926). Portanto, as diferentes classes compartilhavam os trâmueis em espaços concorridos, não no sentido de serem objeto de desejo, mas no sentido de serem disputados corporalmente. Exemplo de costume racializante dissimulado na inexistência de lei segregacionista, a praxe interditava o acesso aos bancos por parte de passageiros descalços (passageiros negros, em outras palavras) ou sem colarinho e gravata, sendo a parte traseira franqueada for all, a popular "cozinha". Os estribos deviam ficar livres (A Tarde, 20/8/1929). 0 excesso de lotação fornecia a chance para a quebra das hierarquias e suas regras espaciais de primeira e segunda classes, renovando as tensões. Homens bem ou mal trajados ocupavam os estribos, incomodando os demais passageiros, especialmente as mulheres, que iam sentadas (brancas ou bem-vestidas) (A Tarde, 19/9/1928, 27/12/1928, 16/7/1929, 23/3/1929, e 20/11/1929). Cumprindo o seu papel de dar voz aos incômodos da elite, nota de jornal se queixa das "cozinheiras imundas" (A Tarde, 26/6/1929). "De roupas engorduradas e temperos malcozidos" - a negra "senta onde bem lhe aprouver, constrangendo [...] quem Ihe ficou junto do mocó" (A Tarde, 20/8/1929). Além da crítica à sua roupa de trabalho, que os patrões talvez não fornecessem nem deixassem lavar e estender em suas residências, a baiana é alvo de descompostura preconceituosa, haja vista já ser notória a sua maestria com temperos (Romo, 2010).

0 excesso de passageiros aumentava o risco de acidentes, em geral ocasionados pela falta de conservação, sem falar nos malogros dos incautos. Era comum os ocupantes do estri- 
bo baterem em postes, caindo em choque, zonzos ou desfalecidos, sob risco de atropelamentos por outros carros (A Tarde, 17/11/1926, 21/12/1926, 3/6/1927, 8/4/1930, 7/5/1930). Os descarrilamentos eram particularmente aterradores em bondes lotados e nos declives das famosas ladeiras da Bahia, como a da Soledade (A Tarde, 24/5/1927, 16/6/1927 e 21/8/1928). Entre os acidentes mais comuns, estavam as quedas no desequilíbrio de pongas e despongas, ginástica de "moleques" trabalhadores, que entregavam embrulhos, merendas e gazetas ( $A$ Tarde, 10/2/1927, 19/3/1928 e 15/8/1930). Excitado pela visita de príncipe hospedado no palácio da Aclamação, Miguel Calmon Sobrinho, ao despongar, caiu e teve a perna ferida pela roda do bonde. Prática masculina que cultivava a destreza física, pongar era ginástica de meninos de classes diferentes. 0 motorneiro, porém, tratado conforme a hierarquia social, foi detido de pronto, mesmo sem nada a ver com o costume da meninada. Magnânimo, o pai do fidalgo, o então governador Góis Calmon, mandou relaxar a prisão (Calasans, 1986: 56). Os atropelos eram a maioria das ocorrências, com vítimas entre idosos, crianças e adultos cujo ofício era desempenhado diariamente, prestadores de ofícios manuais vários (O Imparcial, 4 e 5/6/1926; A Tarde, 2/8/1927, 11/2/1928, 28/9/1928; 15/1/1930; Diário da Bahia, 28/9/1926).

\section{INSEGUROS E CAROS, INCÔMODOS E DISPUTAS}

$\mathrm{T}$ anto a Circular quanto a Elétrica foram adquiridas pela Ebasco no início de 1927, gerando a expectativa de melhorias nos serviços prestados (A Tarde, 11/4/1927). Foram prometidos a automatização do telefone e reparos emergenciais nas termoelétricas de Salvador, na hidroelétrica de Bananeiras em São Félix, onde um novo e maior açude seria construído. Também houve a promessa de reformar o Lacerda e os planos inclinados Gonçalves e Pilar, abrir ramais no Cabula e na Liberdade, afora botar mais carros nos trilhos ( $A$ Tarde, 3 e 25/8/1927; 4 e 28/8/1928; 24/12/1928; 18/2/1929). Em troca, os empresários barganharam a retirada de contrapartidas exigidas à Circular e à Elétrica, a exemplo de confiar seus bens ao município ao término da concessão e da construção de um bom matadouro no Retiro. Os preços dos serviços, para variar, precisavam ser majorados, disseram ${ }^{5}$.

A carestia se agravou com a cobrança dos múltiplos trechos das viagens de bonde. Logo que um primeiro lote de trâmueis passou a rodar, o preço da passagem por trecho duplicou. Assim, os passageiros dos bairros proletários da Liberdade e Itapagipe, além do reajuste do trecho, desembolsavam mais porque tinham cerca de três trechos para pagar (A Tarde, 24/1/1927, 9/2/1928, 18/7/1928 e 15/9/1928). As dores de cabeça não pararam aí. A tudo isso preexistia o velho problema do troco, em vigor nos bondes, planos e elevadores, objeto de reiteradas queixas em 1929 (O Imparcial, 14/4/1926 e 16/5/1926; 
A Tarde, 29/4/1927; 13/4/1929; 3/7/1929). Chegou-se a suspeitar de a falta de troco ser malversação da Circular para extorquir os passageiros (A Tarde, 25/7/1929). 0 conflito não ficava só na disputa pelo dinheiro miúdo, valores risíveis aos olhos de qualquer engenheiro estadunidense residente na cidade. Nesses problemas de troco ou tráfego, condutores e motorneiros eram referidos pelos repórteres e usuários como "malcriados", vezeiramente identificados por sua "carapinha" preta. Do outro lado, havia alguém "estrangeiro", "cavalheiro", "distinto", "pessoa respeitável" ou "senhora" e "senhorinha", "famílias" (O Imparcial, 25/5/1926; A Tarde, 29/4/1929; 10/2/193; 21/2/1930). Duas ocorrências em abril de 1929, em bonde da Barra e noutro da Graça, dão nitidez a essas diferenças. No primeiro, o condutor, "pardavasco velho", "feições talhadas a foice", travou "violenta discussão" com uma "senhora de trajes modestos" e "modos acanhados". No da Graça, o empregado da Linha Circular dirigiu "graçolas pesadas" a "cavalheiros estrangeiros" interessados em informações sobre horários (A Tarde, 29/4/1927).

Vistas de longe ou de cima, as compridas filas eram chamadas de "piolhos-de-cobra", outro nome para lacraia (A Tarde, 3/8/1927). Era aí onde agiam fura-filas e ocorriam empurrões. Nos bondes, o que começava com uma discussão entre passageiro e empregado da Circular poderia virar uma discussão coletiva entre clientela e firma (A Tarde, 12/7/1929). Nisso poderia ocorrer quebra-quebra se o impasse esquentasse e a polícia não aparecesse logo. Em abril de 1927, passageiros de um bonde superlotado para Brotas altercaram, na rua J. J. Seabra, com os funcionários que se recusavam a baixar o estribo esquerdo. Quando o condutor se ausentou para pedir instruções ao telefone, começou o apedrejamento. Foi preciso piquete de cavalaria para suprimir o protesto (A Tarde, 26/4/1927). Logo depois, um conselheiro e um deputado estadual conseguiram que o prefeito impusesse à Circular o já reiteradamente solicitado bonde extraordinário para Brotas (A Tarde, 27/4/1927).

Em setembro de 1928, o motorneiro de um trâmuei irritou os comparecentes para um enterro quando avisou que não desceria superlotado até a Baixa de Quintas, onde, além do cemitério por destino, ocorriam deslizamentos. Contatado por telefone, o delegado tentou resolver o problema com a Circular. Nesse ínterim, o carro foi destruído. Os passageiros deslocaram-se para a Soledade para quebrar o bonde do horário, mas foram obstados por soldados despachados às pressas (A Tarde, 25/9/1928). Irmandades da Igreja com cemitérios em Quintas solicitaram à Circular melhor serviço funerário (A Tarde, 25/9/1929). Em maio de 1930, na Soledade, repetiu-se o apedrejamento de um trâmuei, parado por desentendimento com o fiscal. Sem a polícia por perto, exigiam a partida do bonde, freado por causa do risco de choque com veículo que subia a estrada da Liberdade, que não comportava mão dupla. Conforme o jornal, o ataque foi iniciado por um "pretinho" (A Tarde, 23/5/1930). 
À medida que os efeitos da Grande Depressão se instalaram e espalharam, mais as empresas faltaram, por um lado, com seus compromissos de investir, conservar e reparar, honrando 0 acordo de fornecer serviços de qualidade à população. Por outro lado, reajustes não faltaram. Atingida uma meta prevista nos termos contratuais, novos preços eram baixados. Após a reabertura do Lacerda em setembro de 1930, o preço aumentou em $100 \%$. A isso se somou o anúncio de melhor telefonia com tarifas $200 \%$ mais caras, levando a insatisfação aos comerciantes (A Tarde, 27/8/1930) ${ }^{6}$. Logo em seguida, fecharam os planos inclinados do Gonçalves e Pilar, alongando as filas, espaços de sociabilidade entre baianos ( $A$ Tarde, 3/9/1930). Então, apesar de a joia rara da engenharia mundial ser nova e boa, milhares de usuários se apertavam na hora do corre-corre e empurra-empurra porque os planos inclinados não funcionavam.

A documentação disponível enfatiza a falta de coerção como fator de incentivo e difusão. De fato, o livro do proeminente professor Luís Henrique Dias Tavares, que está pontilhado de inúmeros conflitos resolvidos a bala pela polícia, não faz sua vezeira anotação sobre a chegada de piquete da Força Pública, com mortos e feridos ao término. Mesmo assim, 0 autor dá notícia da ação policial na confrontação com o jornal $A$ Tarde e no fim do quebra-quebra, quando a repressão aparece para dissolver grupos dispersos (Tavares, 2008: 382). Por sua vez, o cônsul dos Estados Unidos Lawrence Briggs observou que os empregados da Circular e da Elétrica não as protegeram direito, pois, só depois de destruídas, eles contactaram 0 Consulado e a Força Pública. Também conforme o seu relato, o secretário de Segurança Pública Madureira de Pinho ordenara à polícia que não interviesse nem disparasse, se não fosse atacada. Seu medo era o $19^{\circ}$ Batalhão de Caçadores reagir à intervenção policial e lançar a Bahia no complô. Desconfiando da infiltração tenentista, que de fato havia, o secretário não queria ver o batalhão fora dos quartéis, podendo distribuir armas à população ${ }^{7}$. 0 governador interino Frederico Costa era tido como alvo fácil de qualquer levante, até mesmo policial, o que pode ter reforçado sua cautela ${ }^{8}$. É importante lembrar que as ordens dadas à polícia foram praticamente simultâneas à confirmação dos alertas da irrupção da luta armada no Recife. 0 filho do secretário de política recorda-se de seu pai ter perdido o cargo dias depois. Pediu demissão ao saber da nomeação de Pedro Gordilho, delegado especial incumbido de combater o mudancismo. Sua "reputação" de "violência e arbitrariedade" ressoava o seu comando em batidas conhecidas pela truculência (Pinho, 1974: 94).

Os protestos começaram nas obras da firma Christiani \& Nielsen, contratadas pela Ebasco no Plano Inclinado Gonçalves. Conta-se que uma aglomeração se formou contra o uso desrespeitoso da bandeira brasileira, estendida entre tapumes, supostamente pelos gringos, sendo isto a gota d'água. A firma e um operário assumiram a responsabilidade, mas isso não 
aplacou o descontentamento, como foi dito depois de tudo consumado ${ }^{9}$. Decerto, esse é um indício a ser considerado seriamente, no sentido de se perceber no ar a raiva que provocava o serviço ruim cobrado caro por estrangeiros. Uma segunda possibilidade a ser considerada é a da flâmula ter servido como bandeira de luta. Defendendo o verde-amarelo, os presentes formaram um primeiro grupo no qual nação, classe e raça puderam fermentar e se unir. Nos jornais publicados posteriormente, o grupo Christiani \& Nielsen eximiria a si mesmo de responsabilidades e também aos contratantes estadunidenses. Admitiu que uma bandeira do Brasil fora estendida, mas para secar ao sol e pelas mãos dos brasileiros, tentaram dizer $(A$ Tarde, 6/10/1930).

Na biografia de Giocondo Dias, apesar de ele, àquela altura, já estar em vias de ser declarado convertido ao comunismo, não há pretensão de ligar o motim ao Partido Comunista Brasileiro (PCB). Giocondo, que entregava o jornal carioca $A$ Nação no porto, encarregava-se de vendê-lo perto do "charriot", como era elegantemente chamado o Plano Inclinado Gonçalves. Nem de graça, em diversas vezes, conseguia passar a folha ao povo. Seja, mesmo assim, sublinhado que, como todo lugar de concentração, o ponto servia para a agitação partidária (Falcão, 1993: 34). Para Briggs, o motivo eram os preços da Circular e da Elétrica. E os funcionários estaduais também estavam com salários atrasados, efeito da Quebra da Bolsa. 0 cônsul apontou também para a propaganda comunista, mas não lhe deu crédito. Embora considerasse o conflito da bandeira um "pretexto", forneceu a junção entre "insatisfeitos" e "agitadores". Foram os protestos que alegavam que o país era desprezado pelos gringos que permitiram aos exaltados convencerem os descontentes a arregaçar as mangas e fazer alguma coisa $^{10}$. A combustão entre proselitismo e descontentamento se desdobrou em "grupos" em marcha na cidade, "fazendo uma suposta demonstração patriótica" ${ }^{11}$. Segundo Jacira Primo (2017), essa manifestação, já se tendo afastado das obras, denunciou na praça Rio Branco o ultraje à bandeira e se dissolveu no Terreiro de Jesus, dada a presença da polícia. Contudo, depois, um grupo compacto formou-se no Terreiro de novo, onde apedrejamentos tiveram lugar perante um delegado. Como não houve repressão, as depredações passaram para os largos Ramos de Queiroz e Rio Branco, atingindo outros pontos até o fim do dia (Diário de Notícias, 5/10/1930).

\section{“DEGENERAÇÃO"}

工 m 1934, o historiador Borges de Barros afirmou em livro que, sem "chefe" para "fazer Eestalar" o movimento revolucionário na noite do dia 4, o levante do $19^{\circ}$ Batalhão de Caçadores foi abortado. Com os militares de braços cruzados, os planos parecem ter ficado nas mãos apenas dos civis. A "ação popular" — embandeirada — "degenerou" em Que- 
bra-Bondes (Barros 1934: 563). A degeneração, já que assim foi escrito, ladeia o registro de Briggs sobre a maioria dos manifestantes consistir em "trabalhadores negros descalços" liderados por estudantes, advogados e jornalistas. São, respectivamente, os suprarreferidos "insatisfeitos" e "agitadores". A suposta liderança, ao perder a condução do protesto para aquela base apenas recrutada para marchar e obedecer, e que não devia levantar o braço em sua defesa, assiste à "degeneração" daquela jornada de luta, premeditada para ser "patriótica". Naquele reduzido mundo do ensino superior brasileiro da década de 30, a mocidade estudantil eram os rapazes das boas famílias baianas. Além de brancos, eram bem tratados por serem oficiais em potencial do Exército, o que atenuava sua repressão pela polícia ${ }^{12}$. Isso instruía a cautela do secretário Madureira de Pinho, evitando assim o impulso de largar a polícia em cima do povo, para não fragilizar sua posição no flanco da competição política com os aliancistas soteropolitanos. Coincidentemente, foi do reagrupamento do protesto em frente da faculdade de Medicina, no terreiro de Jesus, que partiu a primeira pedra.

Professores aliancistas da faculdade podiam ter em seus pupilos as ordenanças para conclamar o povo a se juntar à tropa em luta (assim pensavam), para o que contavam com a agitação panfletária, na imprensa, dos jornalistas. Tavares (2008: 382) comenta a rede de tenentes, médicos e seguidores do ex-governador Seabra, oposta à chapa eleita Vital Soares e Júlio Prestes. Os usuários insatisfeitos com a Circular e a Elétrica, em sua maioria trabalhadores, dirigindo-se à área dos elevadores e dos bondes, podem ter encontrado no fervor de estudantes e doutores a bandeira do quebra-quebra, uma multidão cívica contra a Circular. Enquanto os chefes civis não eram rendidos pelo varonil comando militar, a autoridade sobre a populaça virou o comando da populaça, o que explica o estilo de resistência escolhido. Na edição de 22 de novembro de 1930, em duas palavras a revista francesa L'Illustration resumiu: "ação direta". E o cair da noite revelou (apesar da escuridão) o sujeito capaz de assumir o papel de rebeldia pautado pelo estilo de batalha de rua adotado. Durante o fim do século XIX e o início do XX, a elite baiana se atormentou ao ver navios carregados de proletários europeus tendo São Paulo por destino, a ela cabendo, segundo fonte analisada por Wlamyra Albuquerque (1999: 38), a "maior partilha" do "pernicioso elemento". Também o entrudo era rebaixado como "pernicioso brinquedo" (Silva, 2018: 27). Adicionalmente, futebol, bodoque, jogos de azar e o "perniciosíssimo" jogo do bicho eram como chagas na pele do noturno bicho-papão (Soares, 2019: 54, 57, 63). Na greve geral de Salvador em 1919, temeu-se a difusão das "ideias perniciosas do anarquismo" entre os trabalhadores da construção civil, contágio identificado no regresso do militante negro e libertário Eustáquio Marinho (Guimarães, 2012: 137). 
Com o Recife divido numa luta que durou cerca de três dias, os militares rebeldes do Norte não partiram para uma guerra de movimento sobre a Bahia, manobra já dificultada pelas grandes distâncias do caminho. Com a capital soteropolitana tomada pela multidão plebeia, o setor civil retraiu-se. 0 Quebra-Bondes foi uma das primeiras manifestações populares de rua — talvez a primeira de todas —, no rastilho do estopim de um processo político de ruptura vitorioso depois de 20 dias. Quando ocorreu, não havia nem mesmo um movimento revolucionário publicamente instalado. Diferentemente, a multidão no Rio e em São Paulo, quando foi às ruas, já tinha um palco revolucionário para atuar e, por isso mesmo, foi alvo da cobertura de fotorreportagens nos jornais. Tão distante da revolução como também evidência de sua possível força, o motim mostrou a turbulência da plebe na praça de Salvador e deixou claro, quer para a situação ou oposição baianas, quer para os tenentes do Exército, como o movimento popular podia ser desafiador, levando a trama e as disputas aos limites do imprevisível e do descontrole. Mesmo após estreia retumbante, a Bahia seria posteriormente eleita pelo presidente Washington Luís para confrontar as colunas rebeldes vindas do Norte. Nessa posição, o estado não podia se arriscar a ser abalado pela ressurgência da insubordinação proletária.

\section{AS CINZAS DO DIA 5 E AS JORNADAS SEGUINTES}

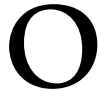

s episódios do dia 4 mostraram que manifestantes podiam abalar a cidade, ameaçar estrangeiros e destruir o sistema de transporte. Se uma revolução estalasse, garagens, usinas, veículos, ascensores e todo o resto poderiam não só cair sob seu controle, mas também se transformar em quartéis ou barricadas. Prudentemente, nos dias seguintes, a cidade receberia tropas despachadas por coronéis para combater qualquer insurgência. Pondo de lado a brutalidade, Gordilho apelou às associações operárias pela criação de batalhões civis. No dia 13, o governo federal situou em Salvador o comando das operações contra os rebeldes do Norte, despachando embarcações militares e tropas do Exército. Essa concentração de forças não retomou as posições já assumidas pela marcha tenentista após a tomada do Recife, mas preveniu um golpe e a reincidência de motins, dando alívio às autoridades baianas e diplomáticas. 0 embaixador dos Estados Unidos pediu ao chanceler Otávio Mangabeira que conservasse em Salvador número de tropas suficiente para dar segurança aos estrangeiros ( $A$ Tarde, 14 e 16/10/1930) $)^{13}$.

Contudo, a Bahia continuaria intranquila no intervalo entre o rescaldo das cinzas dos bondes queimados e a queda do governo no Catete. 0 quebra-quebra minou o poder público pelo medo e emulação que inspirou nos dias seguintes entre os civis. Conforme o Diário de 
Notícias, a população ficou atônita com a explosão popular, acabando por perder a confiança na solidez das autoridades (Diário de Notícias, 10/10/1930), descrença que por si só era um embaraço à manutenção da ordem. Mas o medo não atingia a todos, pois a polícia flagrou rebeldes concentrados na rua Silva Jardim, combinando de queimar o elevador do Taboão em plena luz do dia (A Tarde, 9/10/1930).

Briggs notou nervosismo entre seus conterrâneos, por causa não só dos distúrbios recentes, mas do sentimento "antiamericano" na "classe baixa"14. Para o cônsul, era uma situação difícil, pois os estadunidenses não falavam português, não conformavam uma grande colônia nem possuíam um rol extenso de amigos entre os brasileiros, sendo recém-chegados nas obras da Circular e da Elétrica ${ }^{15}$, aí inclusa a nova barragem de Bananeiras. Assim, dado o estreito contato social, devem ter pressentido xenofobia nos locais de trabalho. De fato, Briggs não deixou de mencionar a presença em Salvador de líderes grevistas demitidos das obras, ao tratar das causas possíveis para o protesto do dia $4^{16}$. 0 cônsul da Grã-Bretanha em Recife, William Mackness, relatou que, desde a constituição do governo revolucionário, técnicos e administradores britânicos eram agredidos e ameaçados em conflitos sucedidos em duas fábricas têxteis. Uma greve seria articulada na ferrovia britânica Great Western ${ }^{17}$.

Mais que isso, Briggs a certa altura admite o risco de, em Salvador, as tropas partirem para repelir os rebeldes e o poder público perder o controle sobre a classe baixa ${ }^{18}$. 0 cônsul inquiriu sua Embaixada, solicitando cruzador da Marinha dos Estados Unidos para socorrer os estadunidenses em caso de necessidade, idêntica demanda do cônsul do Recife ${ }^{19}$. Consultado, o secretário de Estado de Herbert Hoover mostrou-se reticente, sugerindo aos cônsules negociarem com outros diplomatas e autoridades brasileiras a criação de zonas neutras onde acomodar os estrangeiros. Lembrou ainda o recurso a embarcações mercantes como refúgio ${ }^{20}$. 0 Departamento de Estado preocupava-se com a possibilidade de desagradar o governo brasileiro (Smith, 2009: 184), que certamente encararia a aproximação de um cruzador como falta de crédito à sua capacidade de restaurar e manter a ordem.

Briggs reuniu-se com o cônsul alemão, o francês Léon Hippeau e o britânico John Bell para elaborarem plano de evacuação conjunta dos estrangeiros em caso de repetição de distúrbios como o Quebra-Bondes. Hippeau observaria em relatório a Paris que a xenofobia era contra os estadunidenses e que os negócios franceses não seriam prejudicados ${ }^{21}$. Bell diria 0 mesmo ao Foreign Office sobre os interesses britânicos, acrescentando que os membros da colônia que mais conheciam o país só viam perigo em caso de bombardeio de Salvador. Os dois cônsules, diplomaticamente, não se negaram a cooperar. Diferente de Hippeau, para Bell a xenofobia era geral, pois as classes baixas nem sempre distinguiam entre alemães, britânicos, franceses e estadunidenses ${ }^{22}$. Mais difícil era diferenciar o inglês estadunidense do britânico, 
tornando "ingleses" farinha do mesmo saco dos "americanos", o que talvez explique a maior sensibilidade de Bell em relação à xenofobia.

Briggs dirigiu novo e urgente pedido de cruzador militar a 17 de outubro, depois de tropas do Exército e polícia serem deslocadas para repelir os rebeldes em Alagoinhas, ficando Salvador policiada pelos trabalhadores da capital e interior recrutados para Gordilho ${ }^{23}$. Esse contingente, sob as ordens do novo secretário de polícia, não inspirava confiança em Briggs e — ato contínuo — os cônsules britânico e alemão dirigiram-se aos seus governos com o mesmo pedido ${ }^{24}$. É óbvio que, no seu cálculo, a capital estava militarmente mal amparada pelas forças legalistas. Tendo penetrado o território baiano em duas colunas, a marcha tenentista recebia coordenadas diretas de Aracaju, onde estava localizado o quartel-general comandado por Juarez Távora. Blefando ou dizendo a verdade, mas mostrando o perigo percebido por Briggs acerca tanto da retirada das tropas regulares da capital quanto da falta de controle sobre a classe baixa, Gordilho informou à Circular que descobrira plano de outro quebra-quebra, alertando a firma para que não dispusesse de tropas regulares ${ }^{25}$.

Nessa altura, a guerra de movimento era substituída pela guerra de posição. A revolução espremia as forças legalistas sem afã de se engajar em combates, ao passo que a Presidência se enfraquecia. Evidentemente, a tomada do poder se daria no Rio, onde estava 0 Catete, e em São Paulo, de onde viera o presidente eleito. A Bahia, caso se convertesse mesmo em fortim da legalidade, podia, contudo, conter o avanço dos rebeldes no Norte e assediar o território mineiro. Se a luta se alongasse, talvez fossem entregues no porto parte das armas prometidas pelo secretário de Estado estadunidense ao governo brasileiro. As preocupações do cônsul Briggs em Salvador eram outras. Ele estava desinformado desse apoio, soube dele pelos jornais e caracterizou tais notícias como propaganda "antiamericana". Conversadas nas ruas, as novidades poderiam alimentar a impopularidade dos estrangeiros, alertou ${ }^{26}$. Ele, contudo, notou o boato sobre cruzador estadunidense destinado à Bahia para impedir a chegada dos rebeldes e o rebateu em seguida ${ }^{27}$. A atitude indica a persistência de sua preocupação com a xenofobia.

\section{GETÚLIO INTERVÉM NA BAHIA}

Nos dias que marcaram a transição de regime em Salvador, as ruas foram ocupadas pela inflorescência, pública e à luz do dia, do apoio à revolução. No porto, viam-se fundeadas embarcações das nações amigas: Estados Unidos, Alemanha e Grã-Bretanha. Reservadamente, Hippeau atribuiu a essa ostentação a não ocorrência de ataques aos estrangeiros nem às suas propriedades ${ }^{28}$. Improvisaram-se passeatas, comícios, desfiles e outras manifestações indicativas da adesão aos rumos dos acontecimentos. Sob o fervor 
do civismo, também circularam petições e panfletos reivindicatórios da encampação da Circular e da Elétrica, com passageiros afirmando que o preço dos bondes era de 100 e não 200 réis. Muitos circularam sem pagar ${ }^{29}$. Como dito, se a Revolução de 30 tivesse ressoado o clamor popular aceso no Quebra-Bondes, replicando a rebeldia demonstrada pelo povo baiano, seu desfecho seria mais ebuliente e com efeitos bem diversos. Em algum ponto de seus cálculos dissimulados, racializantes e classistas, repercutir a ação popular deve ter sido julgado pernicioso, por assim dizer.

0 problema dos serviços públicos indica como os interventores federais percebiam o papel da revolução na Bahia. 0 aliancista e engenheiro Leopoldo Amaral anunciou ter encarregado especialista de examinar os contratos de luz, água e transporte ${ }^{30}$. Ele decretou a baixa dos aluguéis, o que inspirou a criação do Partido Popular João Pessoa, organizador de comícios e passeatas com inquilinos exigindo respeito à lei. De sua parte, "tipos de barraqueiras baianas que nunca saíram à praça pública, a não ser para acompanhar procissão e para ir à Lapinha, ao Bonfim, ou para fazer Carnaval" participaram de uma passeata contra a Portella Passos \& Cia., sublocatária de barracas no Mercado Modelo (Diário de Notícias, 13/1/1931). 0 interventor renunciaria em meio ao antagonismo dos senhorios, que encaminhariam a Getúlio abaixo-assinado encabeçado pelas irmandades da Igreja, proprietárias de inúmeros imóveis. Dado que Vargas tinha sido instalado no poder com os pareceres de nada consta e nada a obstar das altas cúpulas militares e eclesiásticas, era hora de fazer política palaciana. 0 chefe do governo provisório, que tinha tirado do armário a farda de militar, era apto para entender cristalinamente o pleito das irmandades.

Para substituir Amaral, Távora e os tenentes preferiam um nome militar. Não foram atendidos pelo presidente, que apontou o médico Artur Neiva em fevereiro de 1931. Oriundo de família tradicional, o nome foi bem recebido pela alta sociedade (Diário de Notícias, 5/2/1930). Deixando de lado o decreto supracitado, bem como a revisão dos contratos com as concessionárias, Neiva acreditava ser tarefa do novo regime uma administração eficaz. Com um governo favorável aos Estados Unidos e aos políticos perdedores ${ }^{31}$, concentrou-se em reorganizar a lavoura e reequilibrar o orçamento ${ }^{32}$, realizando cortes de despesas, o que gerou desemprego. Entre as insatisfações acumuladas contra sua gestão, estava a insensibilidade em relação à situação da Circular e da Elétrica ${ }^{33}$. Neiva renunciaria numa situação semelhante às ocorrências do dia 4, isto é, manifestações, comícios e passeatas nas ruas indicavam a iminência de uma quartelada. Com Neiva ainda no cargo, essas manifestações apregoavam nomes para a sucessão e contaram com o Partido Popular João Pessoa (Freitas, 2010: 111) (A Tarde, 17/8/1931) ${ }^{34}$. No dia de sua queda, realizou-se manifestação pela permanência de Pimenta da Cunha na Prefeitura (A Tarde, 17/8/1931), que desde a posse deixara claro seu 
desagrado com o contrato sobre serviços públicos com as concessionárias privadas (A Tarde, 24/2/1931).

No Recife, o cônsul Mackness percebia indícios de o mudancismo ser encarado como oportunidade para trabalhadores fazerem reivindicações. Os 200 empregados da Pernambuco Tramway \& Power engajaram-se na luta armada, mas o estímulo das reivindicações estendera-se aos trabalhadores em geral ${ }^{35}$. Na Bahia, algo equivalente pode ter ocorrido com 0 quebra-quebra do dia 4, pois logo depois da formação do novo governo ocorreram ensaios de greves, sobretudo nas companhias estrangeiras, isto é, na ferrovia Leste, nas docas e na empresa Circular, com o jornal governista de manifesto apoio aos empregados dos bondes. Briggs acusou o primeiro interventor, Leopoldo Amaral, de difundir boatos contra os Estados Unidos para legitimar a revisão do contrato ${ }^{36}$.

Por ocasião da queda de Neiva, participaram ao cônsul que o interventor renunciara por ter medo do "bicho-papão da horda negra". Homens e mulheres famélicos, "apáticos" e "ignorantes" teriam perdido para o exílio os seus chefes, isto é, situação estadual deposta, ficando assim disponíveis à manipulação, feita agora pelos adversários de Neiva. Eram ainda inclinados a descontar seus problemas nos estrangeiros, principalmente na Circular e na Elétrica ${ }^{37}$. Trazido a lume pela pesquisa de Sant'Ana (2010: 93), esse relato de Briggs revela seu olhar racializante, bem como as ansiedades desencadeadas nele, pela revolução, mas também em seus informantes (burgueses, funcionários de carreira) e — hipoteticamente — em Neiva. 0 pressuposto de o exílio ter colocado uma malta de capadócios à disposição de um novo chefe encaixa-se harmonicamente ao modo como Antônio Calmon exercia sua liderança política nas ruas de Salvador. Conforme Calasans (1986: 37), Antoninho — como era chamado na "boca do povo" — tinha "cheiro de povo". Para os adversários era a "negrada de Antoninho Calmon", com quem o chefe permanentemente interagia por meio de uma microeconomia de pequenos favores. Na medida em que o dispositivo militar não compareceu na hora marcada e a agitação acadêmica perdeu o controle sobre a multidão, o estilo de resistência adotado foi o da batalha de rua, que, óbvio, bem pode ter sido o da capoeiragem, para botar para correr quem se opusesse ao seu caminho.

0 apelo a racializantes termos descritores da realidade não acabou quando, enfim, Vargas encontrou em Juracy Magalhães o interventor de que necessitava para enquadrar a Bahia no processo mudancista. Comentando a revolta paulista de 1932, o cunhado do ex-chanceler Mangabeira criticaria o novo chefe político por despachar não só "desocupados, flagelados", mas também "jagunços" para combaterem os constitucionalistas na guerra civil, fazendo da Bahia "África antiga", donde o interventor retirava "escravos para a chacina". Afora o paralelo tênue que pode ser extraído desse trecho - a Bahia volta a fornecer contingentes de seres humanos para servirem à resolução de uma questão em São Paulo (como havia sido com o 
tráfico interprovincial) — as correspondências de Mangabeira fazem alusão a Juracy como 0 "feitor" ${ }^{38}$. Por sua vez, Juracy entraria em rota de colisão com o prefeito Pimenta da Cunha, então no auge de suas disputas com a Circular e a Elétrica, ladeado por choferes, proprietários de pequenas empresas de ônibus e do "zé-povinho"39. Mais uma vez, o problema do transporte público dá a chance para percebermos a presença popular em barganhas eleitorais.

Expomos a hipótese de que, no dia 4 de outubro de 1930, em Salvador, o protesto social tenha escalado diante da ausência da polícia e da retração da hierarquia sociorracial. Seus alvos concretamente traduziram a insatisfação contra as desigualdades sociais exacerbadas pela Crise de 29 e contra o acesso à cidade e seus serviços públicos. 0 quebra-quebra conferiu à revolução vitoriosa um significado específico, isto é, o clamor pela escuta das reclamações dos canteiros de obras, bondes, elevadores, residências e bairros. Dos ascensores, a esperança poderia estender-se às docas; dos bondes, às locomotivas ferroviárias. "Deus nos livre dessa gente, senhora de nossa terra, por direito de assalto", escreveu um padre a Mangabeira sobre os tenentes que depuseram o "pobre Neiva". "Andamos assustados e sem recurso de fuga, em plena estação política da febre de mau caráter, agravada pela 'peste russa', que nos traz aterrorizados" 40 .

\section{NOTAS}

1 Sobre a eletricidade na Bahia, conferir Rebouças (2018).

2 PINHO, E. [Correspondência]. Destinatário: Otávio Mangabeira. Salvador, 21 maio 1932. 1 carta. Publicada em Sampaio (2012: 340).

3 Inquérito Policial de dano à Companhia Linha Circular, 6/10/1930. Arquivo Público do Estado da Bahia (APEB). Briggs ao Department of State (DOS), 25/10/1930. National Archives and Record Administration (NARA). Record Group (RG) 84; Hippeau ao Ministère des Affaires Étrangères (MAE), 10/10/1930. Center des Archives Diplomatiques de Nantes (CADN). 57PO -1 - 8 .

40 trabalho da pesquisa arquivística se define, como aliás nos é ensinado, pelo fichamento in loco, sendo registrado o jornal e sua data completa.

5 Sobre as empresas de serviços públicos na Bahia e sua relação com as autoridades, ver: Saes (2010) e Cunha (2011).

6 Para uma panorâmica histórica sobre o crescimento urbano de Salvador, ver Sampaio (2005).

7 Os conspiradores do batalhão já haviam despertado a atenção de Pinho (Freitas, 2010: 55).

8 Briggs ao DOS, 25/10/1930. NARA. RG 84.

9 Briggs ao DOS, 25/10/1930. NARA. RG 84.

10 Briggs ao DOS, 25/10/1930. NARA. RG 84. 
11 Briggs ao DOS, 25/10/1930. NARA. RG 84.

12 Briggs ao DOS, 25/10/1930. NARA. RG 84.

13 Washington ao DOS, 10/10/1930. NARA. RG 84.

14 Briggs a Washington, 8/10/1930. NARA. RG 84.

15 Briggs ao DOS, 31/10/1930. NARA. RG 84.

16 Briggs a Washington, 25/10/1930. NARA. RG 84.

17 Mackness ao FO, 8/10/1930. FO 371-14200.

18 Briggs a Washington, 10/10/1930. NARA. RG 84.

19 Washington ao DOS, 9/10/1930. NARA. RG 84.

20 DOS a Washington, 9/10/1930. NARA. RG 84.

21 Hippeau ao MAE, 10/10/1930. CADN. 57P0-1-8.

22 Bell ao FO, 13/10/1930. TNA. FO 371-14202.

23 Briggs a Washington, 17/10/1930. NARA. RG 84.

24 Bell ao FO, 18/10/1930. TNA. FO 371-14201.

25 Briggs ao DOS, 25/10/1930. NARA. RG 84.

26 Briggs a Washington, 18/10/1930. NARA. RG 84.

27 Briggs ao DOS, 25/10/1930. NARA. RG 84.

28 Hippeau ao MAE, 4/11/1930. CADN. 57PO - 1 - 8.

29 Briggs ao DOS, 31/10/1930. NARA. RG 84.

30 Briggs ao DOS, 12/12/1930. NARA. RG 84.

31 Briggs ao FO, 25/8/1930. NARA. RG 84.

32 Neiva a Lima, 11/3/1931. CPDOC. Arquivo Hermes Lima. HL 31.03.11 c.

33 Figueiredo a Távora, 11/9/1931. CPDOC. Arquivo Juarez Távora. JT pdf 1930.12.08.

34 Santos a Távora, 24/8/1930. CPDOC. Arquivo Juarez Távora. JT pdf 1930.12.08.

35 Mackness ao FO, 8/10/1930. TNA. FO 371-14200.

36 Briggs ao FO, 20/12/1930. NARA. RG 84.

37 Briggs ao DOS, 22/8/1931. NARA. RG 84.

38 Pinho a Ester e Mangabeira, 17 e 23/9/1932. Publicadas em Sampaio (2012: 391-394).

39 Pinho a Mangabeira e Ester, 21/5/1932. Publicada em Sampaio (2012: 340).

40 Tapiranga a Mangabeira, 9/10/1931. Publicado em Sampaio (2012: 228). 


\section{REFERÊNCIAS}

ALBUQUERQUE, W. Algazarra nas ruas. Comemorações da Independência na Bahia 1889-1923. Campinas: Editora Unicamp, 1999.

BARROS, F. À margem da história da Bahia. Salvador: Imprensa Oficial do Estado, 1934.

BORGES, D. The Family in Bahia, Brazil, 1870-1945. Stanford: Stanford University Press, 1992.

CARVALHO FILHO, A. Um depoimento para a história. Salvado: CEB, 1968.

CALASANS, J. Miguel Calmon Sobrinho e sua época 1912-1967. Salvador: Museu Eugênio Teixeira Leal, 1986.

CUNHA. J. O fazer político da Bahia, 1904-1930. Tese (Doutorado em História) - Universidade Federal da Bahia, Salvador, 2011.

FALCÃO, J. Giocondo Dias: a vida de um revolucionário. Rio de Janeiro: Agir, 1993.

FREITAS, A. Alcance e limites do Movimento Tenentista na Bahia. Dissertação (Mestrado em História) Universidade Federal da Bahia, Salvador, 2010.

GUIMARÃES, L. "Idéias perniciosas do anarquismo" na Bahia. Lutas e organização dos trabalhadores da construção civil (Salvador, 1919-1922). Dissertação (Mestrado em História) - Universidade Federal da Bahia, Salvador, 2012.

LANDES, R. A cidade das mulheres. Rio de Janeiro: Editora UFRJ, 2002.

LIMA, V. (coord.). Getúlio. Uma história oral. Rio de Janeiro: Record, 1986.

LOPES, R. Um Vice-Reinado na República do pós-30. Tese (Doutorado em História) - Fundação Getulio Vargas, Rio de Janeiro, 2014.

MURAKAMI, A. (org.). A Revolução de 30 e seus antecedentes. Rio de Janeiro: Nova Fronteira, 1980.

PINHO, D. M. Carrossel da vida. Rio de Janeiro: J. Olympio, 1974.

PRIMO, J. Tempos vermelhos: Aliança Nacional Libertadora e a política brasileira (1934-1937). Salvador: Editora Sagga, 2017.

REBOUÇAS, D. A cidade da Bahia e a eletricidade. Salvador: Caramurê, 2018.

REIS, J. A Greve Negra de 1857 na Bahia. Revista USP, São Paulo, n. 18, p. 6-29, 1993. https://doi. org/10.11606/issn.2316-9036.v0i18p6-29

ROMO, A. Brazil's Living Museum. Chapel Hill: The University of North Carolina Press, 2010.

SAES, A. Conflitos do capital. Bauru: Edusc, 2010.

SAMPAIO, C. N. 50 anos de urbanização. Salvador da Bahia no século XIX. Rio de Janeiro: Versal, 2005.

SAMPAIO, C. N. (org.). Octávio Mangabeira: cartas do primeiro exílio (1930-1934). Salvador: Fundação Pedro Calmon, 2012. v. 1. 
SANT'ANA, L. H. Os olhares diplomáticos estadunidenses sobre o Brasil em tempos de revolução (19301932). Dissertação (Mestrado em História) - Universidade Federal da Bahia, Salvador, 2010.

SILVA, J. C. Revolução na Bahia. Salvador: EdUFBA, 1980.

SILVA, J. L. O "império das circunstâncias". Carnaval e disputas políticas no pós-abolição (1890-1910). Dissertação (Mestrado em História) - Universidade Federal da Bahia, 2018.

SOARES, I. A jogatina desenfreada. Trabalho, lazer e sociabilidades em Salvador (1890-1920). Dissertação (Mestrado em História) - Universidade Federal da Bahia, Salvador, 2019.

SMITH, J. Unequal Giants: diplomatic relations between United States and Brazil, 1889-1930. Pittsburgh: Pittsburgh University Press, 2009.

TAVARES, L. H. História da Bahia. São Paulo: Edusp, 2008. 